\title{
An Observational Study of Neonates Admitted in NICU of a Tertiary Care Hospital in Rohtas, Bihar
}

\author{
Rambilas Ranjan ${ }^{1}$ \\ ${ }^{1}$ Assistant Professor, Department of Paediatrics, NMCH, Jamuhar, Sasaram.
}

\section{Abstract}

Background: Globally, 2.6 (2.5-2.8) million newborns died in 2016. A High neonatal mortality rate reflects the presence of unfavourable social, economic, and environmental conditions not conducive to neonates. The present study was done to find various factors related to infants morbidity and mortality in a tertiary care centre of Rohtas, Bihar. Subjects and Methods: The present prospective observational study was conducted in the neonatal intensive care unit of a tertiary care centre in Bihar. Data were collected by interview method using a predesigned, semi-structured questionnaire. Results: There were a total of 1030 admissions with pre-term admissions constituted 44.95\%. Majority of admissions was due to LBW (64.17), admitted before 3 days. Majority of neonates (69.02\%) were discharged after medical treatment. Pre-term and related complications were ranked highest (44.95\%). Mortality rates among inborns (10.29\%) and outborns (11.67\%) were nearly similar in the study; there was no significant difference in death rates of inborn and outborn neonates (Chi-square value $=1.22)$. LBW $(8.97 \%)$ neonates were having 2.79 times high mortality than normal. Conclusion: Prematurity, sepsis, and birth asphyxia were accounting for morbidities and mortalities among neonates. The preterm and LBW babies had significantly higher mortality even with standard intensive care; therefore a strong and effective antenatal program with extensive coverage of all pregnant females specifically in outreach areas should be developed which will help in decreasing preterm deliveries and lowering the incidence of LBW babies.

Keywords: Neonatal intensive care unit, Neonatal morbidities, Neonatal mortalities, Rohtas, Bihar.

Corresponding Author: Dr. Rambilas Ranjan, Assistant Professor, Department of Paediatrics, NMCH, Jamuhar, Sasaram.

Received: May 2019

Accepted: May 2019

\section{Introduction}

Worldwide, nearly 7000 neonates die every day. In 2016, 2.6 million newborns died with the range of 2.5 to 2.8 million. Out of all under-five deaths, neonatal deaths account for nearly half of deaths. The percentage share has increased from $41 \%$ in year 2000 to $46 \%$ in 2016 . But the irony is that only five countries account for half of all newborn deaths, namely India, Pakistan, Nigeria, The Democratic Republic of the Congo and Ethiopia. The millennium development goals (MDGs) era ended in 2015 while Sustainable Development goals (SDGs) were implemented in 2016. The SDGs clearly states that no country should have under-five mortality rate more than 25 per 1000 live births by 2030. Ultimately when under-five mortality is contained, neonatal mortality will itself be reduced as it is a major contributing factor. ${ }^{[1,2]}$

Among neonatal deaths, nearly 50\% occur within first 24 hours after birth and $75 \%$ by first seven days. The common causes for these deaths are infection, prematurity and intrapartum-related causes like asphyxia. They contribute to major neonatal complications leading to high morbidity and mortality. According to World Bank report published in 2105 , preterm birth contributed to $85 \%$ of the neonatal mortality, globally. ${ }^{[3-5]}$

Infant mortality rate (IMR) is the most sensitive indicator for health of any community, state or country. High IMR reflects unfavourable social, economic and environmental condition during infancy. The ineffective vital registration system in our country makes it difficult to understand the various causes of high mortality among infants. Also, there is no single solution to save the lives of newborns. We can achieve greater success by combining hospital- and community- based activities on a larger scale. ${ }^{[6-8]}$

Government of India runs many national programmes for the betterment of health of children, especially under-five years of age. Still, there are many loopholes and inadequate care of mother and children contribute to high morbidity and mortality among under-fives generally and infants in particular. A lot of efforts have been done in the field of primary health care to curb IMR. We have achieved good results. The IMR is now reduced to 30 from 49 per 1000 live births. In this endeavour, Neonatal Intensive Care Unit (NICU) has contributed a lot. But, NICU also forms a barrier for the bonding of mother and newborn. Nowadays, there is increased survival of very low birth weight (VLBW) and extremely low birth weight (ELBW) infants due to well equipped centres. Deaths that occur in NICUs have a major impact on IMR. So, understanding the factors for causation 
of deaths in NICUs and morbidity factors associated with death has all the potential to reduce IMR on a large scale. ${ }^{[9-13]}$

There is a paucity of information related to neonates in NICU in this part of Bihar. The present study was done to find various factors related to infants morbidity and mortality in a tertiary care centre of Rohtas, Bihar.

\section{Subjects and Methods}

The present study was a prospective observational study conducted in NICU of a tertiary care hospital in Rohtas, Bihar. Inborn neonates (delivered in the institute of study) as well as out-born cases (delivered outside) referred form all adjacent areas were treated in NICU. All the cases admitted to NICU were included in the study. Data were collected by interview method using a predesigned, semi-structured questionnaire. Neonatal variables used were as follows: total number of admissions, gender, birth weight, and gestational age, diagnosis at admission, final outcome, and duration of stay. Neonates were divided into two groups of inborn and out-born unit admission. The final outcome was recorded as follows: discharged, left against medical advice (LAMA), referred to other centres and death during hospital course. The reasons for admission were determined from the admission notes in the infant's case papers. Mortality data were collected in the form of cause of death, duration between time of admission and death, and age at death. The data were collected for two years, from January 1, 2017 to December 31, 2018 on a daily basis. Intuitional Ethics committee's permission was taken prior the start of the study. The consent from parent/guardian was taken prior start of the study.

Data were analyzed using SPSS version 16.0 which is freely available online. Data were presented as mean and standard deviation and range and categorical data were presented as frequency and percentage. Risk of mortality was calculated using odds ratio (OR) and $95 \%$ confidence interval.

\section{Results}

[Table 1] shows different characteristics of neonates admitted in NICU. There were a total of 1030 admissions during 2017 \& 2018 while inborn neonates were $65.05 \%$, higher than out-born neonates who were $34.95 \%$ to total neonates. Males (640 [62.14\%]) had double the rate of admission as compared to females (390 [37.86\%]). Pre-term admissions constituted $44.95 \%$. Majority of admissions was due to LBW (64.17), followed by normal birth weight (19.91). Majority of neonates were admitted before 3 days. Majority of neonates (69.02\%) were discharged after medical treatment, while 15.06 died due to various complications, $6.6 \%$ Leave against medical advice (LAMA), and $9.32 \%$ were referred to other centres.
[Table 2] depicts morbidity pattern of infants at the time of admission. Pre-term and related complications were ranked highest (44.95\%) followed by other morbidities like IUGR, jaundice, birth asphyxia, sepsis, Meconium aspiration syndrome, respiratory distress and major congenital malformations. [Table 3] shows the mortality pattern of NICU admissions. Prematurity (45.80\%) followed by sepsis (21.29), Hypoxic ischemic encephalopathy (HIE), major congenital malformations and meconium aspiration syndrome were the reasons for mortality among neonates.

[Table 5] depicts association between epidemiological characteristics of neonates and their mortality in NICU. Mortality rates among inborns (10.29\%) and outborns $(11.67 \%)$ were nearly similar in the study; there was no significant difference in death rates of inborn and outborn neonates $($ Chi-square value $=1.22)$. Mortality rates among males $(11.40 \%)$ and females $(10.77 \%)$ were similar in our study. Furthermore, there was no significant differences (Chi-square value $=0.05)$. Pre-term neonates were having high mortality rate with significant difference (Chi-square value $=25.11)$ compared to others. Similarly, LBW $(8.97 \%)$ neonates were having 2.79 times high mortality than normal. It was observed that longer NICU stay (>3 days) improved survival.

Table 1: Background characteristics of neonates admitted in NICU (N=1030)

\begin{tabular}{|l|l|l|}
\hline Characteristics & n (\%) \\
\hline Birth Place & Inborn & $670(65.05)$ \\
\cline { 2 - 3 } & Outborn & $360(34.95)$ \\
\hline \multirow{3}{*}{ Gender } & Males & $640(62.14)$ \\
\cline { 2 - 3 } & Females & $390(37.86)$ \\
\hline Gestation & Term & $567(55.05)$ \\
\cline { 2 - 3 } & Pre-term & $463(44.95)$ \\
\hline Birth Weight & Normal & $205(19.91)$ \\
\cline { 2 - 3 } & LBW & $661(64.17)$ \\
\cline { 2 - 3 } & VLBW & $155(15.05)$ \\
\cline { 2 - 3 } & ELBW & $9(0.87)$ \\
\hline \multirow{5}{*}{ NICU } & $<1$ day & $42(4.08)$ \\
\cline { 2 - 3 } & $1-3$ day & $501(48.64)$ \\
\cline { 2 - 3 } & 4-7 day & $273(26.50)$ \\
\cline { 2 - 3 } & $>7$ day & $214(20.78)$ \\
\hline Outcome & Discharge & $711(69.02)$ \\
\cline { 2 - 3 } & Referral & $96(9.32)$ \\
\cline { 2 - 3 } & LAMA & $68(6.60)$ \\
\cline { 2 - 3 } & Died & $155(15.06)$ \\
\hline
\end{tabular}

Table 2: Morbidity pattern of NICU patients $(\mathrm{N}=1030)$

\begin{tabular}{|l|l|}
\hline Morbidity & n (\%) \\
\hline Prematurity \& related complications & $463(44.95)$ \\
\hline IUGR & $101(9.80)$ \\
\hline Jaundice & $113(10.97)$ \\
\hline Birth asphyxia & $162(15.73)$ \\
\hline Sepsis & $81(7.86)$ \\
\hline Meconium aspiration syndrome & $56(5.43)$ \\
\hline Respiratory distress & $32(3.11)$ \\
\hline Major congenital malformations & $11(1.07)$ \\
\hline Others & $11(1.07)$ \\
\hline
\end{tabular}


Table 3: Mortality pattern of NICU patients $(\mathrm{N}=155)$

\begin{tabular}{|l|c|}
\hline Causes of mortality & $\mathbf{n}(\mathbf{\%})$ \\
\hline Prematurity \& related complications & $71(45.80)$ \\
\hline Sepsis/Pneumonia/ Meningitis & $33(21.29)$ \\
\hline HIE/Moderate-severe Birth asphyxia & $25(16.13)$ \\
\hline Major congenital malformations & $19(12.26)$ \\
\hline Meconium aspiration syndrome & $4(2.58)$ \\
\hline Others & $3(1.94)$ \\
\hline
\end{tabular}

Table 4: Association of characteristics of Neonates with Mortality

\begin{tabular}{|c|c|c|c|c|c|c|c|}
\hline \multicolumn{2}{|c|}{ Characteristics } & $\begin{array}{l}\text { Total } \\
\text { Patien } \\
\text { t }\end{array}$ & $\begin{array}{l}\text { Mortalit } \\
\text { y }(\%)\end{array}$ & Chi & $\begin{array}{l}\mathbf{O} \\
\mathbf{R}\end{array}$ & $\begin{array}{l}95 \\
\% \\
\text { CI }\end{array}$ & $\mathbf{p}$ \\
\hline \multirow[t]{2}{*}{$\begin{array}{l}\text { Birth } \\
\text { Place }\end{array}$} & Inborn & 670 & $\begin{array}{l}69 \\
(10.29)\end{array}$ & \multirow[t]{2}{*}{1.22} & \multirow[t]{2}{*}{$\begin{array}{l}1.1 \\
9\end{array}$} & \multirow{2}{*}{$\begin{array}{l}0.88 \\
- \\
1.52\end{array}$} & \multirow[t]{2}{*}{0.232} \\
\hline & $\begin{array}{l}\text { Out- } \\
\text { born }\end{array}$ & 360 & $\begin{array}{l}42 \\
(11.67)\end{array}$ & & & & \\
\hline \multirow[t]{2}{*}{ Gender } & Male & 640 & $\begin{array}{l}73 \\
(11.40)\end{array}$ & \multirow[t]{2}{*}{0.05} & \multirow[t]{2}{*}{$\begin{array}{l}1.0 \\
8\end{array}$} & \multirow{2}{*}{$\begin{array}{l}0.87 \\
- \\
1.33\end{array}$} & \multirow[t]{2}{*}{0.891} \\
\hline & $\begin{array}{l}\text { Femal } \\
\mathrm{e}\end{array}$ & 390 & $\begin{array}{l}42 \\
(10.77)\end{array}$ & & & & \\
\hline \multirow{2}{*}{$\begin{array}{l}\text { Gestatio } \\
\mathrm{n}\end{array}$} & Term & 567 & $35(6.17)$ & \multirow{2}{*}{$\begin{array}{l}25.1 \\
1\end{array}$} & \multirow{2}{*}{$\begin{array}{l}2.8 \\
3\end{array}$} & \multirow{2}{*}{$\begin{array}{l}2.11 \\
- \\
3.45\end{array}$} & \multirow{2}{*}{$\begin{array}{l}<0.00 \\
1\end{array}$} \\
\hline & $\begin{array}{l}\text { Pre- } \\
\text { term }\end{array}$ & 463 & $\begin{array}{l}83 \\
(17.93)\end{array}$ & & & & \\
\hline \multirow[t]{2}{*}{$\begin{array}{l}\text { Birth } \\
\text { Weight }\end{array}$} & $\begin{array}{l}\text { Norma } \\
1\end{array}$ & 205 & $10(4.87)$ & \multirow[t]{2}{*}{$\begin{array}{l}22.9 \\
1\end{array}$} & \multirow[t]{2}{*}{$\begin{array}{l}2.7 \\
9\end{array}$} & \multirow{2}{*}{$\begin{array}{l}1.83 \\
- \\
4.22\end{array}$} & \multirow[t]{2}{*}{$\begin{array}{l}<0.00 \\
1\end{array}$} \\
\hline & $\begin{array}{l}\text { Others } \\
*\end{array}$ & 825 & 74 (8.97) & & & & \\
\hline \multirow[t]{2}{*}{$\begin{array}{l}\text { Hospital } \\
\text { Stay }\end{array}$} & $\begin{array}{l}<3 \\
\text { days } \\
\end{array}$ & 543 & $\begin{array}{l}72(13.26 \\
)\end{array}$ & \multirow[t]{2}{*}{7.75} & \multirow[t]{2}{*}{$\begin{array}{l}0.6 \\
3\end{array}$} & & \multirow[t]{2}{*}{0.005} \\
\hline & $\begin{array}{l}>3 \\
\text { days }\end{array}$ & 487 & $44(9.03)$ & & & 0.86 & \\
\hline
\end{tabular}

*LBW, VLBW and ELBW

\section{Discussion}

There are a lot of inequities in child mortality across and within countries. As compared to developed countries, neonatal mortality is still high in developing countries. A child in Southern Asia is nine times more likely to die in the 1 st month than a child in a high-income country. The neonatal mortality rate at 25.4 deaths per 1,000 live births in India makes it 12th worst among the 52 lower-middleincome countries. ${ }^{[1]}$ We have tried to present neonatal morbidity pattern and outcome parameters from tertiary care NICU in a neglected state of a developing country.

The present study had more neonates admitted as inborn from this institute. Similar result was found by Malik et al. $(57.21 \%) \cdot{ }^{[14]}$ In our study, there was a gender distribution of males versus females; a study conducted by Saini et al. found similar results (males $=54.56 \%$ vs. females $=$ $45.44 \%) .{ }^{[15]}$ In our study, $55.05 \%$ were term neonates; similar results were obtained from a study by Saharia et al. who found $65.66 \%$ and Modi et al. who found 54.31\%. ${ }^{[16,17]}$ In our study, majority $(64.17 \%)$ of the neonates were Low Birth Weight (LBW) while lower results were obtained in study by Modi et al.(54.24\%), Shridhar et al. found $(40.55 \%) .^{[16,17]}$ In our study, majority of neonates were discharged within 3 days $(52.72 \%)$, while that in the study by Adhikari et al., they found that $47.91 \%$ of neonates were admitted up to 7 days. ${ }^{[12]}$ Majority of neonates $(69.02 \%)$ were discharged after treatment, while higher number of neonates were observed to be discharged in a study by Modi et al. $(88.98 \%) .{ }^{[16]}$

Mortality rates among inborn and outborn were nearly similar in our study, while lower results were obtained by Shridhar et al. (inborn $=6.69 \%$ vs. outborn $=8.36 \%$ ) while Modi et al. ${ }^{[18]}$ found lower mortality rates among outborn $(6.57 \%)$ as compared to inborn (13.22\%) neonates. ${ }^{[16]}$ Proportion of male neonatal mortality was slightly higher as compared to female neonatal mortality, similar results were obtained by Shridhar et al. (males $=59.23 \%$ vs. females $=$ $40.77 \%$ ) in Karnataka, ${ }^{[18]}$ Adhikari et al. in Nepal, ${ }^{[12]}$ while Ranjan et al. found male mortality to be up to $65.30 \%$ in Patna. ${ }^{[19]}$ Pre-term neonatal deaths constituted $17.93 \%$ while Saharia et al. found it to be $17.99 \%,{ }^{[17]}$ Saini et al. found it to be $11.69 \%,{ }^{[15]}$ and Malik et al. found higher (42.63\%) preterm mortality proportion. ${ }^{[14]}$ Mortality due to LBW $(8.97 \% \%)$ was seen in our study, while others have found higher results. Modi et al. found $36.05 \%,{ }^{[16]}$ Prasad et al. found $22.89 \%,{ }^{[20]}$ and Adhikari et al. found $34.78 \% .{ }^{[12]}$ Most of the neonates, those were having with poor outcome, were belonging to premature and LBW groups. Prematurity and birth weight are important factors in determining the survival of neonates in NICU; as in our study, preterm neonates had roughly 3 times' risk of mortality compared with term neonates $(\mathrm{OR}=2.83)$. Similar findings were found by Prasad et al. ${ }^{[20]}$ and Malik et al. ${ }^{[14]}$ In addition, birth weight $<2500 \mathrm{~g}$ was also having roughly 3 times' risk of mortality compared with term neonates $(\mathrm{OR}=2.79)$. Malik et al. found OR of 2.68. ${ }^{[14]}$ The present study had a survival rate of $69.02 \%$ in the NICU. A little higher results were found by Ranjan et al. (76.62\%). ${ }^{[19]}$

\section{Conclusion}

We have tried to present neonatal morbidity pattern and outcome parameters from a tertiary care neonatal center in Rohtas, Bihar. In 2017 \& 2018, a total of 1030 NICU admissions took place. Out of these, 155 (15.06\%) died. Prematurity, sepsis, and birth asphyxia were accounting for morbidities and mortalities. The preterm and LBW babies had significantly higher mortality even with standard intensive care; therefore a strong and effective antenatal program with extensive coverage of all pregnant females specifically in outreach areas should be developed which will help in decreasing preterm deliveries and lowering the incidence of LBW babies.

\section{Limitations}

The findings of the current study should be interpreted keeping in view the following limitations: Neonates who were LAMA and those who were referred to other centers due to non-availability of NICU beds and need of surgical 
intervention were excluded from the study and inclusion of the same could have modified the results. As it was a private hospital-based study and as most of the patients had a mixed socio-economic status, the results of this study may not reflect the true burden which is prevalent in the community as a whole. Maternal details were not studied in the present study. In our study, early and late neonatal deaths were not specified. We were unable to diagnose inborn errors of metabolism due to lack of diagnostic facilities in this institution.

\section{References}

1. UNICEF. Child Mortality 2017. 3 UN Plaza, New York, New York, 10017 USA: UNICEF; 2017. p. 1-40.

2. Liu L, Oza S, Hogan D, Chu Y, Perin J, Zhu J, et al. Global, regional and national causes of under five mortality in 2000-2015. An updated systemic analysis with implications for the Sustainable Development Goals. Lancet 2016;388:3027-35

3. Hedstrom A, Ryman T, Otai C, Nyonyintono J, Mcadams RM, Lester D. Demographics, clinical characteristics and neonatal outcomes in a rural Ugandan NICU. BMC Pregnancy Childbirth 2014;14:1-9.

4. Shrestha S, Singh SD. Outcome of preterm babies and associated risk factors in a hospital. J Nepal Med Assoc 2010;49:286-90.

5. Cupen K, Barran A, Singh V, Dialsingh I. Risk factors associated with preterm neonatal mortality: A case study using data from Mt. Hope women's hospital in Trinidad and Tobago. Children 2017;4:1-10

6. Weldearegawi B, Melaku YA, Abera SF, Ashebir Y, Haile F, Mulugeta A, et al. Infant mortality and causes of infant deaths in rural Ethiopia: A population-based cohort of 3684 births. BMC Public Health 2015;15:17.

7. Fottrell E, Osrin D, Alcock G, Azad K, Bapat U, Beard J, et al. Causespecific neonatal mortality: Analysis of 3772 neonatal deaths in Nepal, Bangladesh, Malawi and India. Arch Dis Child Fetal Neonatal Ed 2015;1000:F439-47.

8. Enweronu-laryea CC, Nkyekyer K, Rodrigues OP. The impact of improved neonatal intensive care facilities on referral pattern and outcome at a teaching hospital in Ghana. J Perinatol 2008;28:561-5.

9. USAID. India's Reproductive, Maternal, Newborn, Child, and Adolescent Health (RMNCH + A) Strategy; 2014. p. 1-44.

10. International Institute for Population Sciences. National Family Health Survey (NFHS-4); 2015. p. 1-666.

11. Al-Wassia H, Saber M. Admission of term infants to the neonatal intensive care unit in a Saudi tertiary teaching hospital: Cumulative incidence and risk factors. Ann Saudi Med 2017;37:420-4.

12. Adhikari S, Rao KS, Ganesh BK, Bahadur N. Morbidities and outcome of a neonatal intensive care in Western Nepal. J Nepal Heal Res Counc 2017;15:141-5.

13. Jacob J, Kamitsuka M, Clark RH, Kelleher AS, Spitzer AR. Etiologies of NICU Deaths. Pediatrics 2015;135:59-71.

14. Malik S, Gohiya P, Khan IA. Morbidity profile and mortality of neonates admitted in neonatal intensive care unit of a central India teaching institute: A prospective observational study. J Clin Neonatol 2016;6:168-73.

15. Saini N, Chhabra S, Chhabra S, Garg L, Garg N. Pattern of neonatal morbidity and mortality: A prospective study in a district hospital in urban India. J Clin Neonatol 2016;5:183-8.

16. Rohit M, Bhavesh M, Punitha KM. Study of the morbidity and the mortality pattern in the neonatal intensive care unit at a tertiary care teaching hospital in Gandhinagar district, India. J Res Med Dent Sci 2015;3:208-12.

17. Saharia N, Deka A, Vivekananda M. Mortality and morbidity pattern of neonatal ICU of Gauhati Medical College and Hospital. IOSR J Dent Med Sci 2016;15:73-5.

18. Sridhar PV, Thammanna PS, Sandeep M. Morbidity pattern and hospital outcome of neonates admitted in a tertiary care teaching hospital, Mandya. Int J Sci Study 2015;3:126-9.

19. Ranjan A, Singh A, Ranjan A, Pediatr JC. Pattern of morbidity and mortality of neonates admitted in tertiary level neonatal intensive care unit in Nalanda Medical College and. Int $\mathrm{J}$ Contemp Pediatr 2016;3:854-7.

20. Prasad V, Singh N. Causes of morbidity and mortality in neonates in Government Medical College, Haldwaniin Kumaun Region (Uttarakhand), India. J Pharm Biomed Sci 2011;9:7-10.

Copyright: (C) the author(s), 2019. It is an open-access article distributed under the terms of the Creative Commons Attribution License (CC BY 4.0), which permits authors to retain ownership of the copyright for their content, and allow anyone to download, reuse, reprint, modify, distribute and/or copy the content as long as the original authors and source are cited.

How to cite this article: Ranjan R. An Observational Study of Neonates Admitted in NICU of a Tertiary Care Hospital in Rohtas, Bihar. Asian J. Clin. Pediatr. Neonatol.2019;7(2):13-16.

DOI: dx.doi.org/10.21276/ajcpn.2019.7.2.4

Source of Support: Nil, Conflict of Interest: None declared. 